\title{
Predictive Value of Serum Uric Acid Levels on Mortality in Acute Coronary Syndrome Patients with Chronic Kidney Disease after Drug-Eluting Stent Implantation
}

\author{
Zhaoxia Yin $^{\mathrm{a}}$ Zhe Fang $^{\mathrm{b}}$ Ming Yang $^{\mathrm{a}}$ Xueping $\mathrm{Du}^{\mathrm{a}}$ Bin Nie ${ }^{\mathrm{b}} \mathrm{Kang} \mathrm{Gao}^{\mathrm{a}}$

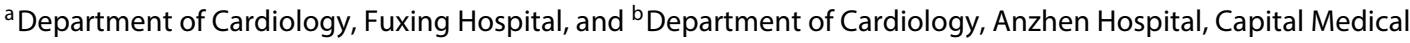 \\ University, Beijing, China
}

For editorial comment see p. 201

\section{Key Words}

Uric acid · Acute coronary syndrome - Chronic kidney

disease · Drug-eluting stent $\cdot$ Survival

\begin{abstract}
Objectives: Despite optimal treatments, prognosis in acute coronary syndrome (ACS) patients with chronic kidney disease (CKD) remains poor. Elevated serum uric acid (SUA) levels may predict worse outcomes in these patients. The objective was to assess the predictive value of SUA levels on mortality in ACS patients with CKD after drug-eluting stent (DES) implantation. Methods: We retrospectively assessed ACS patients with CKD who underwent successful DES implantation between January 2007 and December 2009. Patients were followed up from January to March 2012. CKD was defined as an estimated glomerular filtration rate $<60$ $\mathrm{ml} / \mathrm{min} / 1.73 \mathrm{~m}^{2}$. We assessed the association between SUA levels and mortality. Results: A total of 1,132 patients were included. The mean age was 67.7 years. During a mean follow-up of 38.5 months, 145 patients died: 50 from cardiac diseases, 28 from cerebral diseases, 14 from renal diseases and 53 from other causes. After adjustment for confounders, SUA levels increased the risk of all-cause, cerebral and other-cause mortality. Adjusted hazard ratios for quartiles 3 and 4 versus quartile 1 of SUA were: all-cause, 1.66 [95\%
\end{abstract}

\section{KARGER}

(c) 2013 S. Karger AG, Basel

0008-6312/13/1254-0204\$38.00/0

E-Mail karger@karger.com

www.karger.com/crd confidence interval (Cl) 1.08-2.78] and $1.99(95 \% \mathrm{Cl} 1.21-$ 3.23); cerebral, 2.24 (95\% Cl 0.43-11.7) and $5.89(95 \% \mathrm{Cl}$ 1.30-26.6); and other causes, 2.81 (95\% Cl 1.17-6.78) and 3.89 (95\% Cl 1.63-9.29), respectively. SUA levels had no impact on cardiac and renal mortality rates. Conclusions: High SUA levels are associated with all-cause, cerebral and othercause mortality rates in ACS patients with CKD after DES implantation. Future research is needed to determine if lowering SUA levels will decrease mortality in these patients.

Copyright $\odot 2013$ S. Karger AG, Basel

\section{Introduction}

Despite optimal therapy and revascularization in acute coronary syndrome (ACS) patients with chronic kidney disease (CKD), prognosis remains poor $[1,2]$. Recently, studies showed that serum uric acid (SUA) levels predict adverse outcomes in patients with ACS undergoing percutaneous coronary intervention (PCI) [3, 4]. Increased SUA levels are common in CKD patients and it might represent an additional risk factor in these patients $[5,6]$. There are currently few data available on the association between SUA levels and mortality among ACS patients with concomitant $\mathrm{CKD}$ invasively treated using a drug- 
eluting stent (DES). The aim of the present study was to investigate if an association exists between SUA levels and all-cause mortality in CKD patients after DES implantation for ACS.

\section{Methods}

\section{Patients}

We retrospectively assessed 1,783 consecutive CKD patients who underwent successful DES implantation for ACS between January 2007 and December 2009 in Fuxing Hospital and in Anzhen Hospital, Capital Medical University, Beijing, China. Successful DES implantation was defined as residual narrowing of $<20 \%$ of the lesion and thrombolysis in myocardial infarction (TIMI) grade 3 flow. ACS included: unstable angina pectoris, ST-segment depression and ST-segment elevation acute myocardial infarctions (AMIs). CKD was defined as an estimated glomerular filtration rate (eGFR) of $<60 \mathrm{ml} / \mathrm{min} / 1.73 \mathrm{~m}^{2}$. eGFR $\left(\mathrm{ml} / \mathrm{min} / 1.73 \mathrm{~m}^{2}\right)$ was calculated as follows: $175 \times$ [serum creatinine level $(\mathrm{mg} / \mathrm{dl})]^{-1.234} \times[\text { age (years) }]^{-0.179} \times 0.79$ (if female), which is the Modification of Diet in Renal Disease equation to which a racial factor for the Chinese population was added [7].

A total of 651 patients were excluded: (1) dialytic or renal transplantation patients before enrollment; (2) congenital or valvular heart disease patients; (3) severe in-hospital complication after DES implantation (major bleeding, urgent coronary artery bypass grafting, abrupt occlusion and cardiac rupture); (4) death within 3 months after DES implantation; (5) cancer or gouty patients; (6) patients using agents such as allopurinol or uricosuric; and (7) patients who were lost to follow-up or were unwilling to participate in follow-up.

SUA levels and other laboratory data were measured at patient admission using a Hitachi G600-120 Automatic Analyzer. Typical proteinuria dipstick measurements were performed and quantified as: none, traces, $1+, 2+$ and $3+$, corresponding to urinary protein levels of $<0.1,0.1-0.3,0.31-1.0,1.01-3.0$ and $>3.0 \mathrm{~g} / \mathrm{l}$, respectively. Proteinuria was defined as $1+$ score or more.

Incomplete revascularization was defined as lesions with nonrevascularized vessels $>2.5 \mathrm{~mm}$ and $\geq 70 \%$ stenosis.

\section{Follow-Up}

From January to March 2012, all patient outcomes were followed up from their medical chart. All patients who did not have a cause of death recorded in their medical chart were interviewed by telephone by trained medical staff to simply confirm that they were still alive and that they did not develop another chronic disease treated in other hospitals. For the patients who did not die in the two hospitals participating in the present study $(n=47)$, cause of death was confirmed by relatives.

Cardiac death was defined as death caused by coronary artery disease (CAD), cardiac arrhythmia or congestive heart failure. Sudden unexpected death in previously stable patients was considered cardiac death. Cerebral death included ischemic stroke and hemorrhagic stroke. Renal death was defined as death from renal failure. Renal failure included: (1) the progression of kidney disease from any cause (doubling of baseline serum creatinine levels and/or terminal renal failure); (2) the need for dialysis; (3) the need for kidney transplantation.

Serum Uric Acid on Mortality in ACS Patients with CKD

\section{Statistical Analyses}

Patients were divided into quartiles according to their baseline SUA levels. Normally distributed continuous variables are expressed as means \pm standard deviation. Non-normally distributed variables are presented as medians and interquartile range. Categorical data are expressed as proportions. ANOVA and $\chi^{2}$ tests were used to compare variables across SUA quartiles. Cox's proportional hazards analyses were performed to assess mortality risks. Cumulative event curves were plotted using the Kaplan-Meier survival method and differences between curves were tested for statistical significance using the log-rank analysis. Multivariable Cox proportional hazards regression models were used to assess the independent association of SUA levels with mortality. In multivariate analyses, all baseline clinical and biochemical covariates with a $\mathrm{p}$ value $<0.20$ in univariate analyses and other known clinical risk factors were included in the Cox model. Plots of $\log [-\log$ (survival rate) $]$ against $\log$ (survival time) were constructed to examine the appropriateness of the proportionality assumption. The following variables were dichotomized for multivariate analyses: anemia (hemoglobin cut point of $13.0 \mathrm{~g} / \mathrm{dl}$ for men and $12.0 \mathrm{~g} / \mathrm{dl}$ for women), body mass index (BMI, cut point of 24), albumin (cut point of $35 \mathrm{~g} / \mathrm{l}$ ), eGFR (cut point of $45 \mathrm{ml} / \mathrm{min} / 1.73 \mathrm{~m}^{2}$ ), and left ventricular ejection fraction (LVEF, cutpoint of $40 \%$ ). Results are presented as hazard ratios (HRs) with 95\% confidence intervals (CIs). p values $<0.05$ were considered statistically significant. Data were analyzed using SPSS 17 for Windows (SPSS Inc., Chicago, Ill., USA).

\section{Results}

\section{Patient Characteristics}

A total of 1,132 patients were included in the present study: $812(71.7 \%)$ men and $320(28.3 \%)$ women; 417 patients $(36.8 \%)$ had AMI and the remaining 715 patients $(63.2 \%)$ had unstable angina pectoris. The mean age was $67.7 \pm 7.8$ years (range $37-89$ ). Twenty-four patients $(2.1 \%)$ had an eGFR $<14 \mathrm{ml} / \mathrm{min} / 1.73 \mathrm{~m}^{2}, 121$ patients $\left(10.7 \%\right.$ ) had an eGFR of $15-29 \mathrm{ml} / \mathrm{min} / 1.73 \mathrm{~m}^{2}$ and the remaining 987 patients $(87.2 \%)$ had an eGFR of $30-$ $59 \mathrm{ml} / \mathrm{min} / 1.73 \mathrm{~m}^{2}$. SUA levels ranged from 185.5 to $892.6 \mu \mathrm{mol} / \mathrm{l}$. The mean SUA level was $465.4 \pm$ $113.6 \mu \mathrm{mol} / \mathrm{l}$. The median SUA level was $457.3 \mu \mathrm{mol} / \mathrm{l}$, and the interquartile range was 384.1-534.0. Figure 1 shows the distribution of SUA levels.

Patients' clinical and biochemical characteristics according to SUA quartiles are shown in tables 1 and 2 . Compared with those in the lowest quartile, patients in the highest SUA quartile were more likely to be male, suffered more from hypertension, diabetes mellitus and impaired kidney function, had a higher proportion of LVEF $<40 \%$, had a higher proportion with proteinuria, and used more diuretics (20-40 mg/day). 
Fig. 1. Distribution of baseline SUA levels in 1,132 ACS patients with CKS after DES implantation.

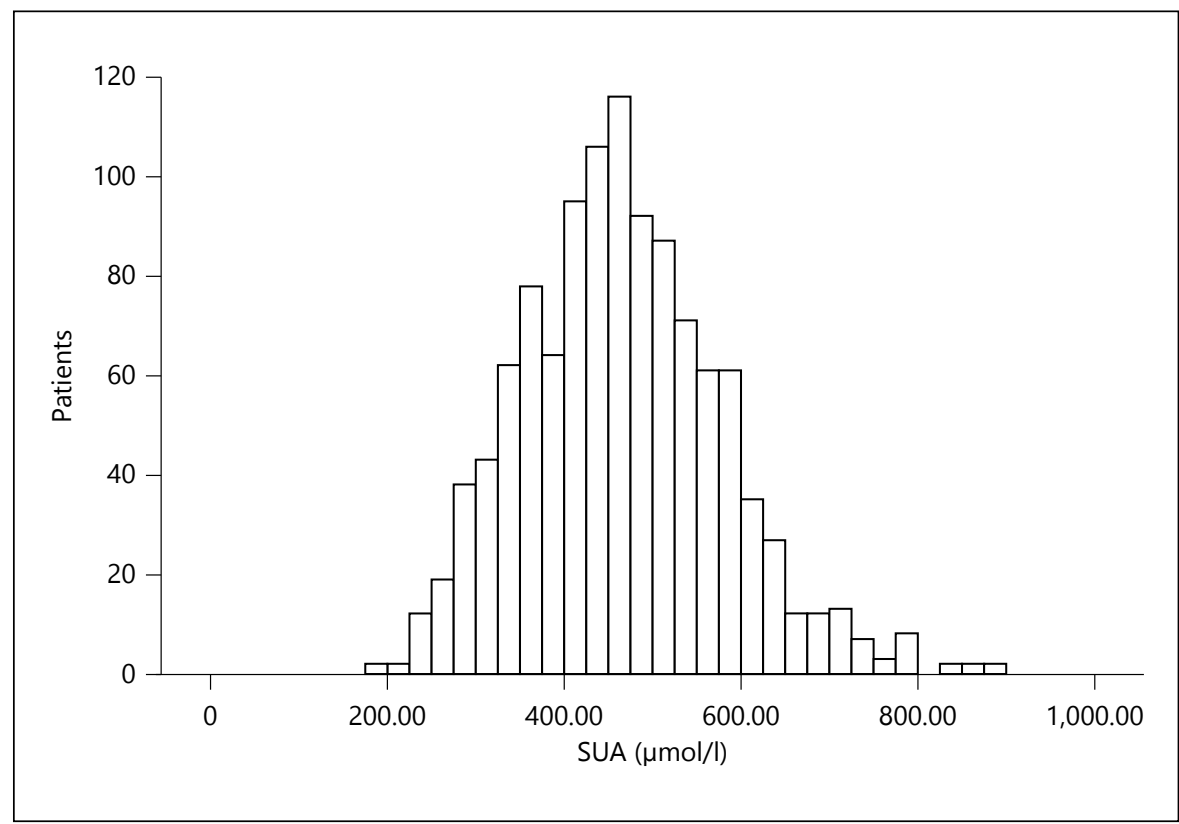

Table 1. Clinical characteristics of patients by quartiles of SUA concentration on admission

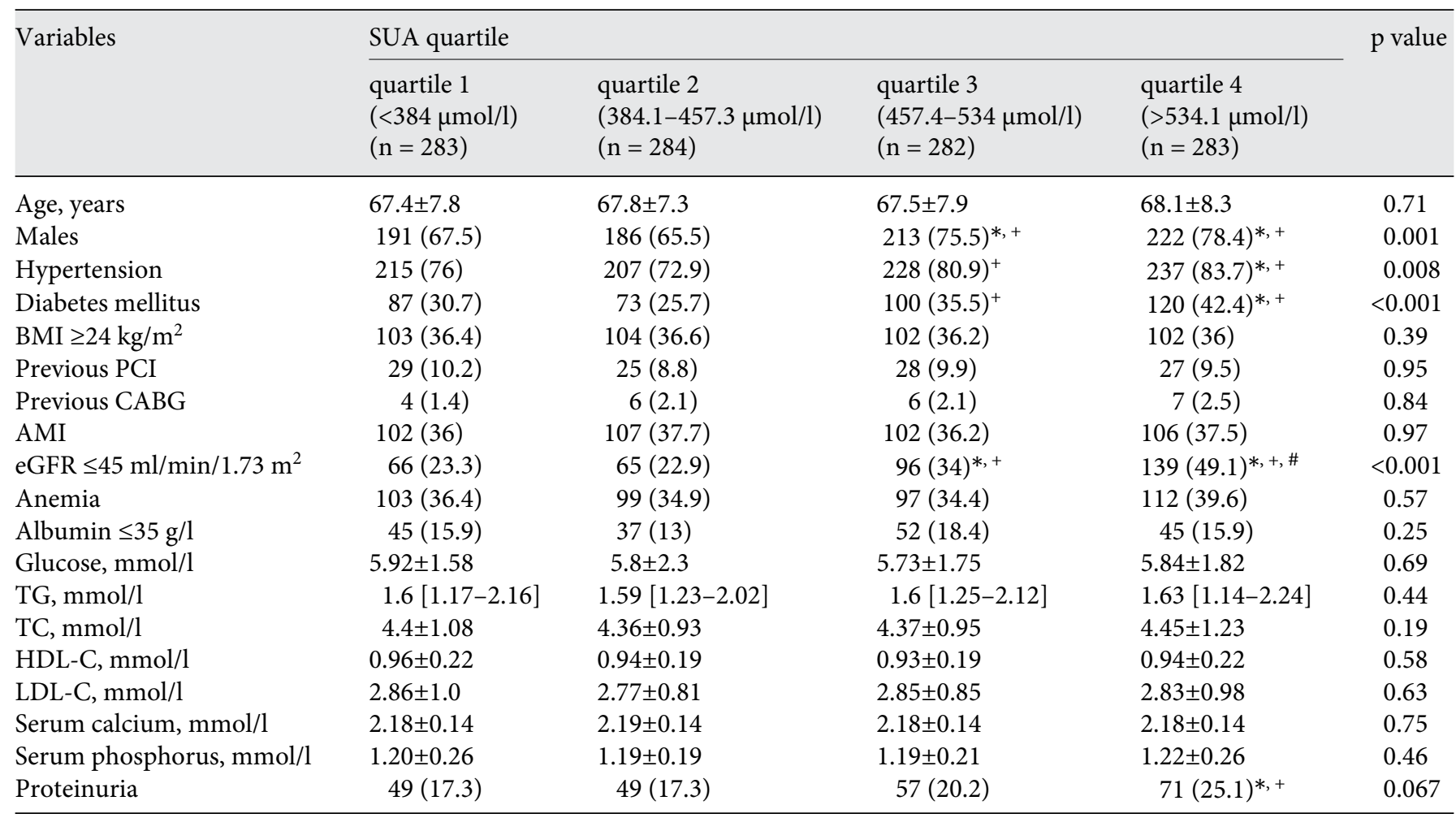

Values are presented as the mean \pm SD or $\mathrm{n}(\%)$. Figures in brackets are ranges. Continuous data were analyzed using ANOVA. Categorical data were analyzed using $\chi^{2}$ tests. BMI: Body mass index; PCI = percutaneous coronary intervention; $\mathrm{CABG}=$ coronary artery bypass graft; AMI: acute myocardial infarction; TG = triglycerides; TC = total cholesterol; HDL-C = high-density lipoprotein cholesterol; LDL-C = low-density lipoprotein cholesterol.

${ }^{*} \mathrm{p}<0.05$ from quartile $1{ }^{+} \mathrm{p}<0.05$ from quartile $2{ }^{*} \mathrm{p}<0.05$ from quartile 3 . 
Table 2. Patient characteristics at discharge, according to SUA level quartiles

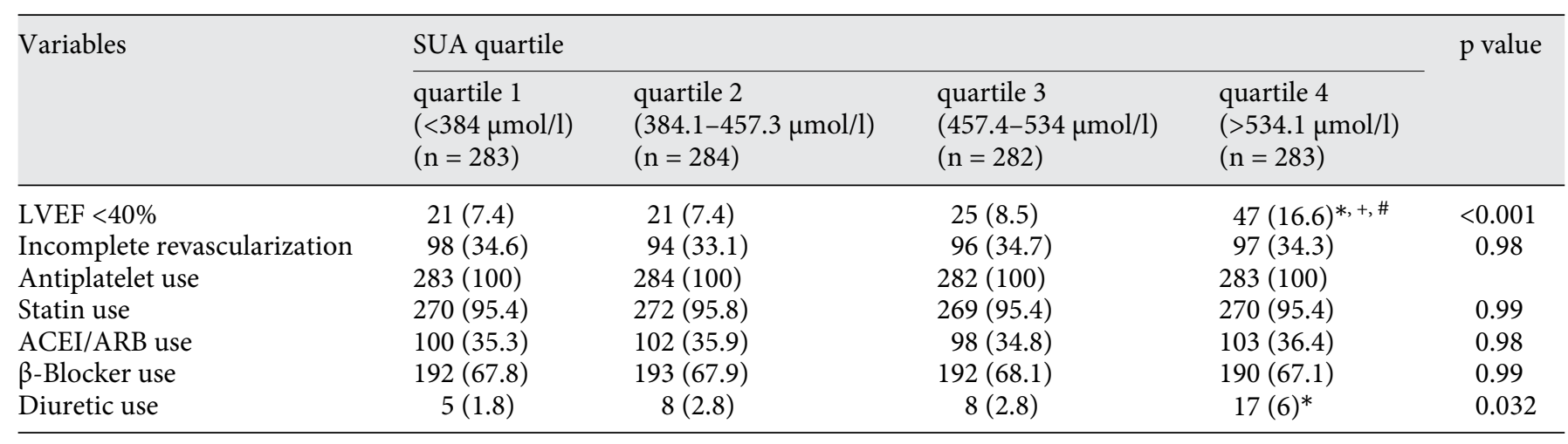

Results are presented as $\mathrm{n}(\%)$. Categorical data were analyzed using $\chi^{2}$ tests. LVEF $=$ Left ventricular ejection fraction; ACEI $=$ angiotensin-converting enzyme inhibitor; $\mathrm{ARB}=$ angiotensin receptor blocker.

${ }^{*} \mathrm{p}<0.05$ from quartile $1{ }^{+} \mathrm{p}<0.05$ from quartile $2{ }^{*} \mathrm{p}<0.05$ from quartile 3 .

Table 3. Mortality by quartile of SUA as assessed by univariate Cox proportional hazards models

\begin{tabular}{|c|c|c|c|c|}
\hline & Quartile 1 & Quartile 2 & Quartile 3 & Quartile 4 \\
\hline \multirow{2}{*}{$\begin{array}{l}\text { All-cause mortality } \\
\text { p value }\end{array}$} & \multirow[t]{2}{*}{1.0} & $0.85(0.46-1.54)$ & $1.94(1.18-3.19)$ & $2.89(1.8-4.66)$ \\
\hline & & 0.58 & 0.009 & $<0.001$ \\
\hline $\begin{array}{l}\text { Cardiac mortality } \\
\text { p value }\end{array}$ & 1.0 & 0.45 & 0.26 & 0.55 \\
\hline $\begin{array}{l}\text { Cerebral mortality } \\
\text { p value }\end{array}$ & 1.0 & $2.12(0.39-11.57)$ & $2.72(0.53-14.0)$ & $9.98(2.30-43.3)$ \\
\hline $\begin{array}{l}\text { Renal mortality } \\
\text { p value }\end{array}$ & 1.0 & 0.22 & 0.22 & 0.48 \\
\hline \multirow{2}{*}{$\begin{array}{l}\text { Other mortality } \\
\text { p value }\end{array}$} & \multirow[t]{2}{*}{1.0} & $0.61(0.18-2.08)$ & $2.78(1.16-6.66)$ & $4.21(1.81-9.75)$ \\
\hline & & 0.43 & 0.02 & 0.001 \\
\hline
\end{tabular}

Results are presented as HRs, with 95\% CIs in parentheses. In this univariat Cox regression analysis, quartile 1 was set as the reference and compared with other groups (quartiles 2, 3 and 4).

\section{Mortality Rates}

During a mean follow-up of 38.5 months (range 4-60), 611 patients $(54 \%)$ were hospitalized again and 145 patients died. The all-cause mortality rate was $12.8 \%$ $(145 / 1,132)$. The causes of death were: cardiac death $(\mathrm{n}=$ $50)$, cerebral death $(\mathrm{n}=28)$, renal death $(\mathrm{n}=14)$, other death $(n=53)$.

Using univariate Cox regression analyses, compared with the first SUA quartile, higher SUA levels were significantly associated with an increased risk of all-cause mortality (quartiles 3 and $4 ; \mathrm{p}<0.01$ ), cerebral mortality (4th quartile; $\mathrm{p}=0.002$ ) and mortality from other causes (quartiles 3 and $4 ; \mathrm{p}<0.03$; table 3 ). The cumulative sur- vival rates of each event categories that occurred during follow-up were compared using a Kaplan-Meier curve, according to SUA quartiles (fig. 2, 3).

All variables with a $p$ value $<0.20$ in univariate analyses (age, gender, diabetes mellitus, eGFR, LVEF, SUA and proteinuria) were further analyzed using multivariate regression analyses to adjust HRs. In addition, extra variables (including AMI, serum albumin, hemoglobin, BMI and incomplete revascularization) were included for total mortality analysis; AMI and incomplete revascularization were included for cardiac mortality analysis, and BMI, hemoglobin and serum albumin were included for cerebrovascular and renal mortality. After ad- 


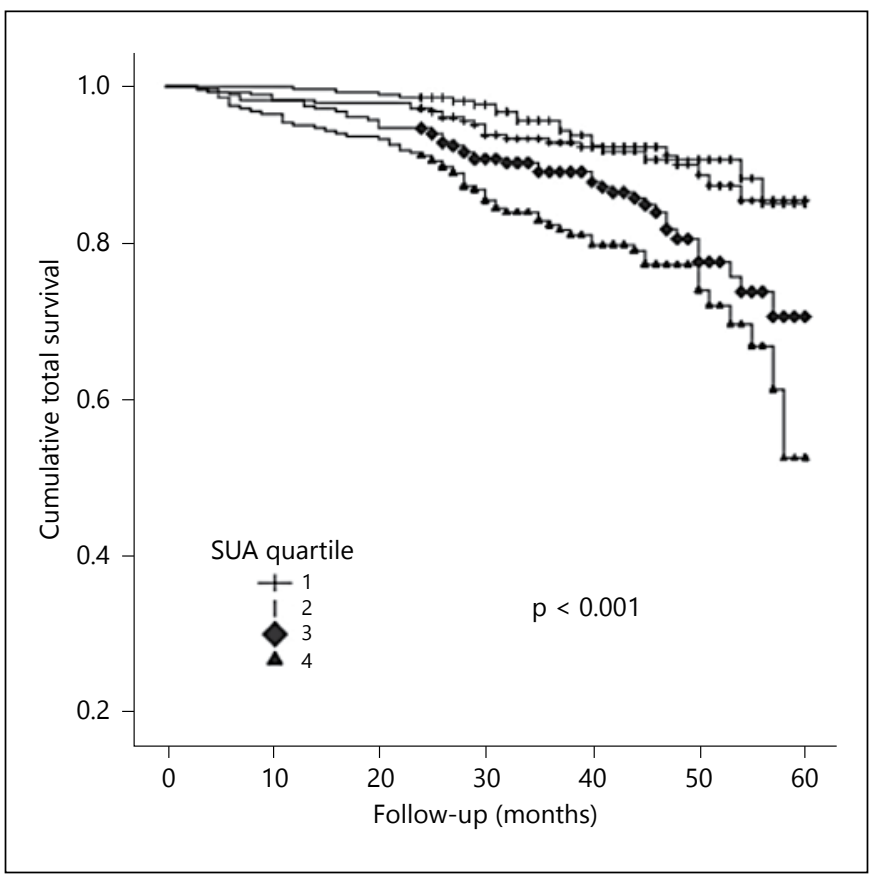

Fig. 2. Overall survival analysis grouped according to SUA level quartiles.

justment for these variables, the associations between SUA quartiles and mortality rates remained the same (table 4).

\section{Discussion}

The present study showed that SUA levels are high in Chinese ACS patients with CKD. After ACS treatment using DES implantation, higher SUA levels were associated with all-cause mortality, cerebral mortality and mortality from other causes, but not with cardiac and renal mortality. These associations remained significant after adjustment for factors known to influence mortality, showing a statistical tendency to differ between SUA level groups.

With the rapidly increasing obesity and metabolic syndrome incidences, hyperuricemia is very frequent in the general Chinese adult population [8-10]. Due to progressive loss of the GFR, patients with end-stage renal disease have decreased renal clearance of uric acid and then have higher SUA levels. Mean SUA levels of maintenance hemodialysis patients were $456 \mu \mathrm{mol} / \mathrm{l}$ in the study by Ifudu et al. [11] and $462 \mu \mathrm{mol} / \mathrm{l}$ in the study by Hsu et al. [12]. In the present study, SUA levels were comparable to those of patients with end-stage renal disease from previous studies.

An increasing number of studies demonstrated the relationship between SUA levels and CAD patients [1316]. However, the relationship between SUA levels and clinical outcomes in CKD patients remains controversial. Some studies showed a 'J-shaped' relationship between SUA levels and all-cause mortality in hemodialysis or stage 5 CKD patients $[12,17]$, but this observation is controversial [18]. Weiner et al. [19] showed that SUA levels were not independent predictors of myocardial infarction outcomes, stroke outcomes and all-cause mortality in 1,678 patients with CKD. Moreover, Navaneethan and Beddhu [20] reported a significant association between hyperuricemia and mortality in non-CKD patients. The presence of CKD attenuates the associations of SUA with mortality. Some studies demonstrated that SUA levels were associated with increased cardiovascular risk and mortality in CKD patients $[6,21]$. However, there are little data about the relationship in patients with concomitant ACS and CKD, especially in those undergoing DES implantation.

In ACS patients with CKD after successful DES implantation, our present study showed that patients with higher SUA levels had higher all-cause mortality, which is in agreement with the studies presented above. Further analyses indicated that this relationship was mainly due to cerebral mortality and mortality from other causes, rather than to cardiac and renal mortality, even after adjustment for relevant confounders.

There are growing evidences for relationships between SUA levels and cerebral mortality in elderly patients. In the CASTEL study [22], stroke was the first cardiovascular cause of death in 3,282 subjects aged $>65$ years, and higher SUA levels increased the risk of mortality from stroke (relative risk 1.61; CI 1.14-2.10). In Chinese patients, high stroke morbidity and mortality were observed, and SUA levels were also related to cerebral mortality $[23,24]$. This may explain our results about the relationship between SUA and cerebral mortality, since a large proportion of the patients in the present study were elderly. It has been hypothesized that the antioxidant properties of SUA may protect general deterioration and cancer [25], however, some studies showed different results. Heras et al. [26] observed that SUA levels were independent risk factors for mortality in elderly patients, mainly from general deterioration. Strasak et al. [27] showed that increased SUA levels were independently related to an increased risk of cancer mortality in men and women. Similarly, we observed that SUA levels were in- 


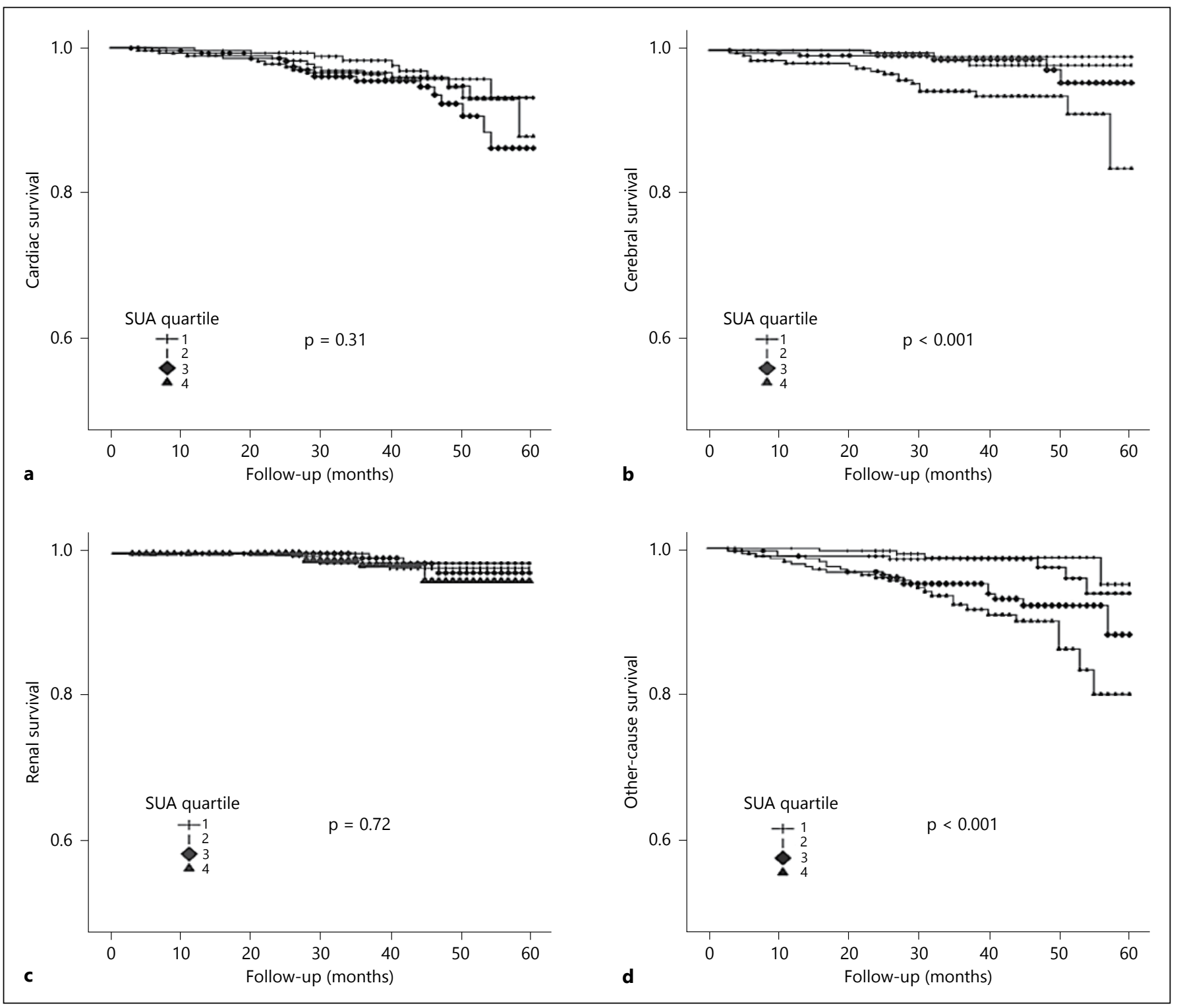

Fig. 3. Survival analysis for cardiac (a), cerebral (b), renal (c) and other-cause (d) survival grouped according to SUA level quartiles.

dependent risk factors for these other causes of mortality, such as general deterioration, cancer and infections. Since mortality determination does not need assessment of SUA levels, and the analysis in this study is the relationship between baseline SUA levels and various causes of mortality during follow-up, the possibility of the baseline SUA level as a marker of mortality can be excluded.

Recently, some data showed that SUA levels predicted worse prognosis in ACS patients undergoing PCI [3, 4, 15]. Brodov et al. [15] reported that the highest SUA quintile showed worse cardiovascular outcomes (HR
$1.46,95 \%$ CI 1.04-2.06; $\mathrm{p}=0.005)$, but most of these patients did not receive DES. Kaya et al. [3] demonstrated in 2,249 patients with ST-segment elevation myocardial infarction who underwent primary PCI that high SUA levels were independent predictors of major adverse cardiac events in the hospital (odds ratio 2.03, 95\% CI 1.253.75; $\mathrm{p}=0.006$ ) and during long-term follow-up (odds ratio $1.64,95 \%$ CI $1.05-2.56 ; \mathrm{p}=0.03$ ). They suggested that SUA levels at admission were an additional biomarker associated with in-hospital adverse outcomes, as well as with long-term outcomes. However, in the study by 
Table 4. Mortality by quintiles of SUA as assessed by multivariable Cox proportional hazards models

\begin{tabular}{|c|c|c|c|c|c|}
\hline Mortality & & Quartile 1 & Quartile 2 & Quartile 3 & Quartile 4 \\
\hline All-cause & $\begin{array}{l}\text { HR } \\
\text { p value }\end{array}$ & 1.0 & $\begin{array}{l}0.88(0.48-1.62) \\
0.69\end{array}$ & $\begin{array}{l}1.66(1.08-2.78) \\
0.045\end{array}$ & $\begin{array}{l}1.99(1.21-3.23) \\
0.007\end{array}$ \\
\hline Cardiac & $\begin{array}{l}\text { HR } \\
\text { p value }\end{array}$ & 1.0 & $\begin{array}{l}0.76(0.31-1.87) \\
0.55\end{array}$ & $\begin{array}{l}1.34(0.64-2.82) \\
0.44\end{array}$ & $\begin{array}{l}0.84(0.37-1.89) \\
0.68\end{array}$ \\
\hline Cerebral & $\begin{array}{l}\mathrm{HR} \\
\mathrm{p} \text { value }\end{array}$ & 1.0 & $\begin{array}{l}2.29(0.42-12.6) \\
0.34\end{array}$ & $\begin{array}{l}2.24(0.43-11.7) \\
0.34\end{array}$ & $\begin{array}{l}5.89(1.30-26.6) \\
0.02\end{array}$ \\
\hline Renal & $\begin{array}{l}\text { HR } \\
p \text { value }\end{array}$ & 1.0 & $\begin{array}{l}1.23(0.23-6.49) \\
0.81\end{array}$ & $\begin{array}{l}0.59(0.11-3.33) \\
0.55\end{array}$ & $\begin{array}{l}0.54(0.11-2.65) \\
0.45\end{array}$ \\
\hline Other causes & $\begin{array}{l}\mathrm{HR} \\
\mathrm{p} \text { value }\end{array}$ & 1.0 & $\begin{array}{l}0.60(0.18-2.06) \\
0.42\end{array}$ & $\begin{array}{l}2.81(1.17-6.78) \\
0.02\end{array}$ & $\begin{array}{l}3.89(1.63-9.29) \\
0.002\end{array}$ \\
\hline
\end{tabular}

Figures in parentheses are 95\% CIs. In this multivariate Cox regression analysis, quartile 1 was set as the reference and compared with other groups (quartiles 2, 3 and 4).

All variables with a $\mathrm{p}$ value $<0.2$ in univariate analyses (age, gender, diabetes mellitus, eGFR, LVEF, SUA and proteinuria) were further analyzed using multivariate regression analyses. In addition, extra variables (including AMI, serum albumin, hemoglobin, BMI and incomplete revascularization) were included for total mortality analysis; AMI and incomplete revascularization were included for cardiac mortality analysis, and BMI, hemoglobin and serum albumin were included for cerebrovascular and renal mortality.

Hemoglobin was dichotomized using cut points of $13.0 \mathrm{~g} / \mathrm{dl}$ for males and $12.0 \mathrm{~g} / \mathrm{dl}$ for females. BMI was dichotomized using a cut point of $24 \mathrm{~kg} / \mathrm{m}^{2}$ (a BMI $<24 \mathrm{~kg} / \mathrm{m}^{2}$ was considered normal and a $\mathrm{BMI} \geq 24 \mathrm{~kg} / \mathrm{m}^{2}$ was considered overweight). Albumin was dichotomized using a cut point of $35 \mathrm{~g} / \mathrm{l}$. eGFR was dichotomized using a cut point of $45 \mathrm{ml} / \mathrm{min} / 1.73 \mathrm{~m}^{2}$. LVEF was dichotomized using a cut point of $40 \%$.
Kaya et al. [3], the renal functions of patients were normal, approximately $97 \%$ of patients had bare metal stents and $80 \%$ of patients showed postprocedural TIMI 3 grade. Rapid restoration of normal blood flow is associated with lower mortality in patients with AMI [28]. Since all patients underwent DES treatment and postprocedural TIMI 3 grade for their heart condition, we cannot exclude the possibility that the treatment interfered with our cardiac mortality results. Though elevated SUA levels had stronger effects on cardiac dysfunction than coronary atherosclerosis in the Japanese Coronary Artery Disease study, Filippatos et al. [29] observed that hyperuricemia had a significant association with poor outcomes in heart failure patients without CKD, but not in those with CKD. They analyzed the mechanisms by which hyperuricemia may predict poor outcomes and showed that it was when hyperuricemia was the result of increased xanthineoxidase activity and not when it was primarily due to impaired renal uric acid excretion. In addition, Strasak et al. [30] showed that SUA levels were more strongly related to mortality from chronic heart failure in younger individuals than in older individuals. Maybe these could explain why SUA levels were not related to cardiac mortality in CKD patients in the present study.
High SUA levels were once considered as being the result of kidney dysfunction instead of the cause for CKD development and progression [31]. However, Mok et al. [32] showed in nearly 15,000 subjects that elevated SUA levels increased the risk of developing CKD which was defined as doubling of baseline serum creatinine levels and/or terminal renal failure, not mortality. In the study by Liu et al. [33], hyperuricemia was not a risk factor for renal replacement therapy (HR 0.96, 95\% CI 0.79-1.16). Inrig et al. [34] observed that among CKD patients treated for ACS using PCI, the mortality risk greatly outweighed the risk of reduced eGFR or development of endstage renal disease following ACS. Different definitions had different outcomes. In our study, there was no relationship between SUA and mortality of renal causes. The use of statins reduces cardiac mortality and renal progression [35]. In our study, some patients died of cardiovascular death before renal function could deteriorate, which could introduce a bias. Thus, these factors may have affected our results. We need a larger sample size and longer follow-up time to improve the assessment of the relationship between SUA and renal death. Also, many factors are responsible for mortality in CKD patients even after DES implantation. Future researches are needed to 
determine whether lowering SUA levels decrease these patients' non-cardiac mortality, especially in older patients.

\section{Limitations}

This study has several limitations. First, since this was a retrospective study, some data on mortality were unavailable and many patients were thus lost to analyses. However, most of our patients were followed up in our hospitals or were able to inform us correctly. Second, treatments during follow-up were not clear, especially in cases of long-term follow-up. Third, the study was based on baseline SUA levels, and SUA level assessments were not performed during follow-up. However, we believe that baseline SUA levels at presentation reflects the pathological processes already in place, and thus, gives us clues about patients' clinical evolution. The present study was a retrospective study aiming to assess the impact of baseline SUA levels at presentation (levels unmodified by different treatments) with survival of ACS patients with CKD. Due to the large sample size, SUA levels were not uniformly performed during follow-up of the different patients. Fourth, most of the enrolled patients were older, which could have influenced analyses. Finally, serial eGFR data were not necessarily available for all patients to assess renal function deterioration. If these data had been available, more cases of renal death could probably have been observed, and a significant relation between SUA levels and renal death might have been observed.

\section{Conclusion}

SUA levels are high in Chinese ACS patients with CKD. Even though they are treated using DES implantation, higher SUA levels are associated with all-cause mortality during follow-up, mainly cerebral and other-cause mortality, rather than cardiac and renal mortality. Future researches are needed to determine if decreasing SUA levels decreases these patients' non-cardiac mortality, especially in older patients.

\section{References}

>1 Dohi T, Miyauchi K, Okazaki S, Yokoyama T, Tamura H, Kojima T, Yokoyama K, Kurata T, Daida $\mathrm{H}$ : Long-term impact of mild chronic kidney disease in patients with acute coronary syndrome undergoing percutaneous coronary interventions. Nephrol Dial Transplant 2011;26:2906-2911.

2 Bevc S, Penko M, Kanic V, Hojs R: Mortality of patients with renal dysfunction after percutaneous coronary intervention. Angiology 2010;61:24-30.

>3 Kaya MG, Uyarel H, Akpek M, Kalay N, Ergelen M, Ayhan E, Isik T, Cicek G, Elcik D, Sahin Ö, Cosgun SM, Oguzhan A, Eren M, Gibson CM: Prognostic value of uric acid in patients with ST-elevated myocardial infarction undergoing primary coronary intervention. Am J Cardiol 2012;109: 486-491.

4 Ndrepepa G, Braun S, Haase HU, Schulz S, Ranftl S, Hadamitzky M, Mehilli J, Schömig A, Kastrati A: Prognostic value of uric acid in patients with acute coronary syndromes. Am J Cardiol 2012;109:1260-1265.

$>5$ Madero M, Sarnak MJ, Wang X, Greene T, Beck GJ, Kusek JW, Collins AJ, Levey AS, Menon V: Uric acid and long-term outcomes in CKD. Am J Kidney Dis 2009;53:796-803.

-6 Neri L, Rocca Rey LA, Lentine KL, Hinyard LJ, Pinsky B, Xiao H, Dukes J, Schnitzler MA: Joint association of hyperuricemia and reduced GFR on cardiovascular morbidity: a historical cohort study based on laboratory and claims data from a national insurance provider. Am J Kidney Dis 2011;58:398-408.

$>7$ Ma YC, Zuo L, Chen JH, Luo Q, Yu XQ, Li Y, $\mathrm{Xu}$ JS, Huang SM, Wang LN, Huang W, Wang M, Xu GB, Wang HY: Modified glomerular filtration rate estimating equation for Chinese patients with chronic kidney disease. J Am Soc Nephrol 2006;17:2937-2944.

-8 Cai Z, Xu X, Wu X, Zhou C, Li D: Hyperuricemia and the metabolic syndrome in Hangzhou. Asia Pac J Clin Nutr 2009;18:81-87.

$\checkmark 9$ Chien KL, Hsu HC, Sung FC, Su TC, Chen MF, Lee YT: Metabolic syndrome as a risk factor for coronary heart disease and stroke: an 11-year prospective cohort in Taiwan community. Atherosclerosis 2007;194:214-221.

$>10$ Lee MS, Lin SC, Chang HY, Lyu LC, Tsai KS, Pan WH: High prevalence of hyperuricemia in elderly Taiwanese. Asia Pac J Clin Nutr 2005; 14:285-292.

-11 Ifudu O, Tan CC, Dulin AL, Delano BG, Friedman EA: Gouty arthritis in end-stage renal disease: clinical course and rarity of new cases. Am J Kidney Dis 1994;23:347-351.

12 Hsu SP, Pai MF, Peng YS, Chiang CK, Ho TI, Hung KY: Serum uric acid levels show a 'Jshaped' association with all-cause mortality in haemodialysis patients. Nephrol Dial Transplant 2004;19:457-462.

13 Kim SY, Guevara JP, Kim KM, Choi H, Heitjan DF, Albert DA: Hyperuricemia and coro- nary heart disease: a systematic review and meta-analysis. Arthritis Care Res 2010;62: 170-180

14 Okura T, Higaki J, Kurata M, Irita J, Miyoshi K, Yamazaki T, Hayashi D, Kohro T: Elevated serum uric acid is an independent predictor for cardiovascular events in patients with severe coronary artery stenosis. Subanalysis of the Japanese Coronary Artery Disease (JCAD) Study. Circ J 2009;73:885-891.

15 Brodov Y, Chouraqui P, Goldenberg I, Boyko V, Mandelzweig L, Behar S: Serum uric acid for risk stratification of patients with coronary artery disease. Cardiology 2009;114: 300-305.

-16 Spoon DB, Lerman A, Rule AD, Prasad A, Lennon RJ, Holmes DR, Rihal CS: The association of serum uric acid levels with outcomes following percutaneous coronary intervention. J Interv Cardiol 2010;23:277-283.

-17 Suliman ME, Johnson RJ, García-López E, Qureshi AR, Molinaei H, Carrero JJ, Heimbürger O, Bárány P, Axelsson J, Lindholm B, Stenvinkel P: J-shaped mortality relationship for uric acid in CKD. Am J Kidney Dis 2006; 48:761-771.

18 Latif W, Karaboyas A, Tong L, Winchester JF, Arrington CJ, Pisoni RL, Marshall MR, Kleophas W, Levin NW, Sen A, Robinson BM, Saran R: Uric acid levels and all-cause and cardiovascular mortality in the hemodialysis population. Clin J Am Soc Nephrol 2011;6:2470-2477. 
19 Weiner DE, Tighiouart H, Elsayed EF, Griffith JL, Salem DN, Levey AS, Sarnak MJ: The relationship between nontraditional risk factors and outcomes in individuals with stage 3 to 4 CKD. Am J Kidney Dis 2008;51: 212-223.

20 Navaneethan SD, Beddhu S: Associations of serum uric acid with cardiovascular events and mortality in moderate chronic kidney disease. Nephrol Dial Transplant 2009;24:1260-1266.

-21 Madero M, Sarnak MJ, Wang XL, Greene T, Beck GJ, Kusek JW: Uric acid and long-term outcomes in CKD. Am J Kidney Dis 2009;53: 796-803.

-22 Mazza A, Pessina AC, Pavei A, Scarpa R, Tikhonoff V, Casiglia E: Predictors of stroke mortality in elderly people from the general population. Eur J Epidemiol 2001;17:1097-1104.

-23 Chien KL, Hsu HC, Sung FC, Su TC, Chen MF, Lee YT: Hyperuricemia as a risk factor on cardiovascular events in Taiwan: the ChinShan Community Cardiovascular Cohort Study. Atherosclerosis 2005; 183:147-155.

-24 Chen JH, Chuang SY, Chen HJ, Yeh WT, Pan WH: Serum uric acid level as an independent risk factor for all-cause, cardiovascular, and ischemic stroke mortality: a Chinese cohort study. Arthritis Rheum 2009;61:225-232.
5 Strasak AM, Rapp K, Hilbe W, Oberaigner W, Ruttmann E, Concin H, Diem G, Pfeiffer KP, Ulmer $\mathrm{H}$ : The role of serum uric acid as an antioxidant protecting against cancer: prospective study in more than 28000 older Austrian women. Ann Oncol 2007;18:1893-1897.

26 Heras M, Fernández-Reyes MJ, Sánchez R, Molina Á, Rodríguez A, Álvarez-Ude F: Serum uric acid as a marker of all-cause mortality in an elderly patient cohort. Nefrologia 2012;32:67-72.

27 Strasak AM, Rapp K, Hilbe W, Oberaigner W, Ruttmann E, Concin H, Diem G, Pfeiffer KP, Ulmer H: Serum uric acid and risk of cancer mortality in a large prospective male cohort. Cancer Causes Control 2007;18:1021-1029.

28 Akpek M, Kaya MG, Uyarel H, Yarlioglues M, Kalay N, Gunebakmaz O, Dogdu O, Ardic I, Elcik D, Ergelen M, Sahin Ö, Oguzhan A, Ergin A, Gibson CM: The association of serum uric acid levels on coronary flow in patients with STEMI undergoing primary PCI. Atherosclerosis 2011;219:334-341.

29 Filippatos GS, Ahmed M, Gladden JD, Mujib M, Aban IB, Love TE, Sanders PW, Pitt B, Anker SD, Ahmed A: Hyperuricaemia, chronic kidney disease, and outcomes in heart failure: potential mechanistic insights from epidemiological data. Eur Heart J 2011;32:712-720.

30 Strasak A, Ruttmann E, Brant L, Kelleher C, Klenk J, Concin H, Diem G, Pfeiffer K, Ulmer $\mathrm{H}$ : Serum uric acid and risk of cardiovascular mortality: a prospective long-term study of 83,683 Austrian men. Clin Chem 2008;54: 273-284.
31 Filiopoulos V, Hadjiyannakos D, Vlassopoulos D: New insights into uric acid effects on the progression and prognosis of chronic kidney disease. Ren Fail 2012;34:510-520.

- 32 Mok Y, Lee SJ, Kim MS, Cui W, Moon YM Jee SH: Serum uric acid and chronic kidney disease: the Severance cohort study. Nephrol Dial Transplant 2012;27:1831-1835.

33 Liu WC, Hung CC, Chen SC, Yeh SM, Lin MY, Chiu YW, Kuo MC, Chang JM, Hwang SJ, Chen HC: Association of hyperuricemia with renal outcomes, cardiovascular disease, and mortality. Clin J Am Soc Nephrol 2012;7: 541-548.

34 Inrig JK, Patel UD, Briley LP, She L, Gillespie BS, Easton JD, Topol EJ, Szczech LA: Mortality, kidney disease and cardiac procedures following acute coronary syndrome. Nephrol Dial Transplant 2008;23:934-940.

35 Athyros VG, Karagiannis A, Ganotakis ES, Paletas K, Nicolaou V, Bacharoudis G, Tziomalos K, Alexandrides T, Liberopoulos EN, Mikhailidis DP: Association between the changes in renal function and serum uric acid levels during multifactorial intervention and clinical outcome in patients with metabolic syndrome. A post hoc analysis of the ATTEMPT study. Curr Med Res Opin 2011;27: 1659-1668. 